\title{
Eduardo Frei Montalva y las históricas y globales exigencias cívicas del Estado de Derecho $^{1}$
}

\section{Eduardo Frei Montalva and the Historical and Global Civic Demands of the Rule of Law}

\author{
Enrique San Miguel Pérez ${ }^{2}$ \\ Universidad Rey Juan Carlos (España) \\ ORCID: https://orcid.org/0000-0003-0600-5876
}

Recibido: 29-06-2021

Aceptado: 16-09-2021

\section{Resumen}

La rotunda personalidad política de Eduardo Frei Montalva, presidente cristiano-demócrata de Chile entre 1964 y 1970, y líder de la oposición democrática tras la violenta instalación de la dictadura del general Augusto Pinochet en 1973, incluye, ya en su tiempo, un poderoso pensamiento sobre la democracia, el Estado de Derecho y la ciudadanía global, así como el origen y significado de la Historia. Y sus análisis y propuestas conservan plena vigencia política y jurídica.

Palabras-clave: Estado de Derecho, democracia, ciudadanía global, historia, Chile, Eduardo Frei Montalva, Democracia Cristiana, Derechos Humanos.

\footnotetext{
${ }^{1}$ Este artículo se ha elaborado dentro del proyecto de investigación, del que es Investigador Principal, Integración, derechos humanos y ciudadanía global, financiado por el Área de Gobierno de Vicealcaldía del Ayuntamiento de Madrid dentro de la convocatoria pública de subvenciones para proyectos en materia de ciudadanía global y cooperación internacional para el desarrollo (2020), obteniendo el primer lugar entre los proyectos presentados.

2 (enrique.sanmiguel@urjc.es) Doctor en Derecho y en Historia. Profesor de Historia del Derecho en la Universidad Complutense, en donde dirigió el Colegio Mayor Diego de Covarrubias, en 2010 ganó la cátedra de Historia del Derecho y de las Instituciones de la Universidad Rey Juan Carlos, en donde ha desempeñado la secretaría general, la dirección del Servicio de Publicaciones, la dirección de Formación y Cultura de la Fundación Universidad Rey Juan Carlos y la jefatura de la Inspección de Servicios. Investigador y profesor visitante en las Universidades de Edimburgo, Burdeos 3, Hamburgo, París 12, Católica Argentina, Católica de Santa Fe, Miguel de Cervantes de Santiago de Chile, Sergio Arboleda de Bogotá, Católica de Valparaíso y Católica de Puerto Rico. Autor de más de trescientos trabajos científicos, su último libro es La soberanía del derecho sobre la fuerza. Abogacía, justicia y literatura. Dykinson. Madrid. 2021.
} 


\begin{abstract}
The strong political portrait of Eduardo Frei Montalva, the Christiandemocratic presidente of Chile between 1964 and 1970 and, before the violent establishment of general Augusto Pinochet dictatorship regime in 1973, leader of democratic opposition, includes, already in his time, a powerful though about democracy, rule of law, and global citizenship, and about the origin and meaning of history. And his analysis and proposals retain full political and legal validity.
\end{abstract}

Keywords: Rule of Law, democracy, global citizenship, history, Chile, Eduardo Frei Montalva, Christian Democracy, Human Rigths.

\title{
Introducción: la necesidad de un nuevo proyecto histórico para el sistema democrático
}

Estamos convencidos de que el capitalismo representa una concepción materialista e inhumana, que, si bien encarna una técnica de no conocido dinamismo en la expansión económica, no significa lo que pudiéramos llamar un verdadero proyecto de civilización...

La política en pocos años ha dejado de ser local para adquirir dimensiones planetarias. Y al mismo tiempo observamos con temor que se concreta la amenaza de la extinción de los recursos naturales no renovables, la contaminación de los mares, ríos y lagos y la degradación de la atmósfera.

...El Occidente sufre la crisis de su propio éxito. Si tuviéramos tiempo para reflexionar deberíamos quedar atónitos ante el hecho de que la causa de la inquietud que atraviesa el corazón de las naciones prósperas es justamente su prosperidad.

...Resulta ahora que la sociedad de consumo genera en su interior las mayores y más hondas insatisfacciones...

Por eso creemos los que abrazamos una vocación social y humana cuya razón e inspiración está en el Evangelio, que hemos tenido razón al plantear nuestra ruptura con este mundo, con sus injusticias y sus desniveles (Frei Montalva, 1973. Archivo Casa Museo Eduardo Frei Montalva-ACMEFM- 262 EFIN/ $1-04)$

Apenas dos semanas después de su elección como senador por Santiago de Chile, el 15 de mayo de 1973, con una amplísima mayoría, y de su inmediata elección como presidente del Senado el 23 de mayo siguiente, por también amplio margen, 25 votos contra 14 (Gazmuri, 2000: 831), Eduardo Frei Montalva terminaba el 31 de mayo siguiente en su casa en la Calle Hindenburg la que habría de convertirse en Necesidad de un nuevo proyecto histórico, una de las más resonantes intervenciones que habrían de producirse en el 
duodécimo Congreso de la Democracia Cristiana italiana, que entre el 6 y el 10 de junio se celebraría en Roma en medio del "decenio Moro-Berlinguer", y de la expectativa de un compromiso histórico que Enrico Berlinguer habría de calificar en Bolonia el 27 de octubre de ese mismo 1973, ante la Asamblea de las Juventudes Comunistas, como un "esfuerzo de compresión recíproca, de un encuentro y de un acuerdo" (Berlinguer, 1977: 154) antes de que, entre el 16 de marzo y el 9 de mayo de 1978, el secuestro y asesinato de Aldo Moro, querido amigo del propio Eduardo Frei Montalva, además de una "tragedia republicana" (Giovagnoli, 2005: 261 y ss.), deviniera en el cierre del histórico tercio del siglo XX que entre 1945 y 1978 asistió a la refundación del Estado de Derecho gracias a la expansión de los derechos económicos y sociales y a la ampliación de las bases políticas sustentantes del sistema democrático.

Dotado de un inmenso prestigio internacional a lo largo de su histórico y todavía reciente mandato presidencial (1964-1970), y reforzado por sus recientísimos triunfo electoral e instalación al frente de la Cámara Alta, Eduardo Frei Montalva no había sin embargo optado por un discurso de ámbito chileno, a pesar de la crítica situación en la que había dejado el país para viajar a Europa, sino por plantear ante el Congreso de una fuerza partidaria con presencia ininterrumpida en el gobierno en Italia desde 1944, y que representaba la narrativa política edificadora del constitucionalismo europeo de posguerra, social y democrático de Derecho, e igualmente constructora de la integración europea a partir de 1950, un proyecto de renovación integral de la propuesta democrática y, por consiguiente, del funcionamiento del Estado de Derecho, que venía a amplificar el planteamiento que ya, el 21 de noviembre de 1968, y al abandonar la presidencia del Consejo de Ministros tras el denominado con justicia "Gobierno largo", había planteado Aldo Moro al Consejo Nacional de la Democrazia Cristiana con la también muy indicativa denominación Una política per $i$ tempi nuovi, anunciado la existencia de "una nueva humanidad que quiere hacerse realidad" como consecuencia del "movimiento irresistible de la Historia" (Moro, 1969: 10 y ss)

Eduardo Frei Montalva, como Aldo Moro jurista de formación, pero siempre apasionado examinador de la Historia, y muy sensible conocedor de sus corrientes profundas, había comprometido su corazón, pero también su empeño racional, en el concreto contenido histórico de la acción política a través de la solución democrática, y su materialización institucional en el Estado de Derecho. Y esa lectura histórico-jurídica, partiendo de sus específicos condicionamientos latinoamericanos, se convertiría en el sustento de la singular propuesta de "Revolución en Libertad" chilena, sin duda inspirada en la "Revolución a través de la Ley" del Movimiento Republicano Popular francés desde su Congreso fundacional parisino del 25 y 26 de noviembre de 1944, cuyo Manifiesto proponía el desdoblamiento de esa revolución en 
un concreto conjunto de revoluciones: la que permita la elevación moral y espiritual del conjunto de los seres humanos; la que garantice a cada persona una vida en seguridad y dignidad; la que haga de la democracia política y social una plena realidad; la que entregue a una nación los medios para realizar totalmente su destino; la que posibilite la transformación de la estructura del Estado mediante el respeto de la soberanía popular y la libertad de la ciudadanía; la creadora de un Estado liberado "de las potencias del dinero"; la creadora de la seguridad material de cada trabajador asegurando un salario mínimo; y la impulsora de la participación de todas las clases sociales en las riquezas espirituales e intelectuales de la civilización moderna. Y la revolución se realizaría "seriamente, dentro del orden y a través de la ley" (Bichet, 1980: 51-52) El MRP, tras abandonar la posibilidad de constituir una única fuerza representativa del conjunto de la Resistencia al nazismo, nacía como el partido de la Resistencia católica, y proponía una visión del Estado, asumía un mandato histórico e incorporaba una cultura política ofreciendo una identidad basada en la lectura cristiana de la democracia (Letamendía, 1995: 52 y ss.) No sabía Eduardo Frei Montalva que el Partido Demócrata Cristiano chileno habría de reproducir, a partir de 1973, y a lo largo de toda la dictadura pinochetista, la misma función, y en el compromiso con la restauración democrática y el nuevo despliegue democrático del Estado de Derecho a partir de 1990.

\section{Hacer justicia acudiendo a la capacidad transformadora de la democracia: el Estado de Derecho del joven Frei}

Que la Historia era la primera pasión de Eduardo Frei Montalva desde su juventud como estudiante de Derecho es algo que habría de manifestarse en sus primeros libros, comenzando por sus muy juveniles Memorias y Chile desconocido. El jurista que encontró tardíamente su propia vocación profesional y existencial a través de la pasión por la Historia y por la Filosofía descubría una realidad primaria en su mayor parte ignota para los chilenos: su propio país, el mismo que un amigo, camarada y sucesor en la presidencia republicana y democrática, Patricio Aylwin Azócar, habría de calificar en su toma de posesión en el Estadio Nacional el 12 de marzo de 1990 como de "bella pero loca geografía" (Aylwin Azócar, 2018: 427) En Chile desconocido, en 1937, Eduardo Frei se expresaba en términos muy categóricos cuando sostenía que "no es posible crear un espíritu nacional sin conocer las raíces históricas de una patria". Y, ahondando en el mismo razonamiento añadía que un pueblo "para que realice su misión debe encontrar su camino y conocer su significado, su razón de existencia. Sólo penetrando en el alma de una raza y su sentido auténtico se puede encontrar la forma en que un pueblo exprese su contenido. 
Y si esa expresión no se logra se vivirá siempre en una especie de transición o componenda" (Frei Montalva, 2010: 14)

La Política y el Espíritu, publicado en 1940, y el primero de sus grandes libros, venía a representar, en el umbral de la treintena, un ejercicio de despojamiento vital de enorme radicalidad en ese proceso, apostando por "la aceptación voluntaria de la pobreza" y por "renunciar a hacer de la vida un simple negocio económico cuya finalidad es amontonar dinero". El mandato del nuevo histórico proceso civilizatorio que se aproximaba en medio de una contienda mundial que, en el momento de la composición del libro, asistía a la dramática destrucción de algunos de los más sólidos Estados de Derecho del mundo, como era la República Francesa, como consecuencia de la brutal agresión totalitaria, arrojaba profundas e impactantes lecciones históricas para un analista del rigor metódico y la finura de Frei Montalva. Por eso sostenía entonces que "hay que dejar morir todo un universo accidental, es preciso dejar que caigan las cenizas, las molduras, el revestimiento del edificio y saber descubrir sólo la piedra sólida que será fundamento eterno de lo que viene. Habrá quienes lloren sobre los deshechos y se apeguen a ellos; pero hay que dejarlos en su dolor inútil”. Y, en su determinación de las exigencias históricas que trae consigo la democracia que habría de suceder al cataclismo que padecía todo el mundo, el abogado chileno distinguía a un colectivo cuyo comportamiento le suscitaba una muy singular reflexión:

no tienen palabras vivas los cristianos intelectualizados para quienes toda esa verdad es sólo una bella construcción estética en la cual se satisfacen, y que, en cambio, se sienten demasiado cómodos en este mundo que les deja vivir. Para ellos, en su elegante y frío escepticismo, a través de las formas externas de una piedad vacía, no hay posibilidades, y sutilmente querrán oponerse a todo esfuerzo nuevo y vigoroso (Frei Montalva, 1993: 121).

Y casi habría de coincidir la publicación de este libro con una de las fases del despliegue vital e intelectual del joven jurista y pensador más fecundas y de más profunda huella en su identidad cívica, en su pensamiento político, y en el diseño de su proyecto institucional y de gobierno, como consecuencia de su relación con dos figuras gigantescas que cobrarían como amigos e inspiradores de su andadura pública un decisivo impacto en su existencia: Gabriela Mistral y Jacques Maritain. Ese impacto se hará especialmente visible en su correspondencia con ambos, pero muy especialmente con su amiga Gabriela Mistral, la inmensa poeta con la que, como diría Alejandro Zambra, Chile comenzó a competir en un campeonato mundial con el que finalizaría por alzarse, y por dos veces, la segunda con Pablo Neruda: el campeonato mundial de la poesía. Ambos compartían una profunda inquietud social y un no menor profundo compromiso con la transformación de la estructura política 
del país como parte del abordaje en su integridad de la resolución de escándalos democráticos como la desigualdad y la injusticia. Pero el compromiso era, aún, de más amplio radio. En una carta de Eduardo Frei a Gabriela Mistral del 18 de abril de 1940, el joven abogado se refiere también al problema de la necesidad de hacer "un supremo esfuerzo por salir de esta mediocridad oscura y abrumadora". Y le ofrece a la extraordinaria escritora un concreto supuesto:

\begin{abstract}
¿Cómo es posible, por ejemplo, que no haya habido un Gobierno capaz de llamarla a usted para que venga a estar entre nosotros? Puede que algún día la podamos tener en Chile, en una obra limpia y hermosa. Es nuestro sueño, como muchos otros que usted nos ayudaría a soñar mejor. Pero en este país a los que sueñan con algo grande los desprecian, en cambio sólo creen en los realistas, que han resultado ser los más grandes ignorantes de la realidad (Frei Montalva, 1989: 106).
\end{abstract}

Ya en Chile desconocido esa óptica se dibujaba aplicada a la lectura integral del problema social que al futuro presidente habría de acompañar en sus inquietudes de manera permanente, y que habría de presidir un "estudio comprensivo de nuestro pasado": el por qué no existió en el Chile decimonónico una "verdadera clase media" que no nacería hasta después de 1900, y su evolución. Y el razonamiento se coronaba con una deliciosa reflexión última: "más que algunos detalles estúpidos sobre las ideas estratégicas de Duguesclin y la lista exacta de los emperadores romanos y reyes merovingios, nos convendría saber por qué y cómo se han formado en Chile las capas sociales, cómo han evolucionado e influido y cómo y por qué han decaído lamentablemente". Y explica el porqué de esta inquietud cuando adjudica a las clases medias

un papel decisivo en toda sociedad orgánica. Son elemento de equilibrio y fuerza económica e intelectual decisiva. De ahí salen generalmente los tipos de selección y sus virtudes modestas son una considerable reserva moral. Estas clases medias en Europa desempeñan un papel importantísimo. En Chile, sin embargo, no ha sucedido lo mismo. No significó la clase media ese verdadero poder, considerado en toda la amplitud que debía y no representó un aporte valioso en el desarrollo de nuestra nacionalidad (Frei Montalva 2010: 16 y 23)

En este año y sentido, y de manera contemporánea a las reflexiones de Frei, cuando entre el 20 y el 28 de octubre de 1945 se celebró en Florencia la Semana Social de los Católicos de Italia, Giorgio La Pira presentó unas reflexiones que habrían de convertirse en el fundamento de su extraordinaria aportación política e institucional tras su elección el 2 de junio de 1946 como diputado democristiano, e integrante de la Comisión Constitucional. Publicadas bajo la denominación de Examen de conciencia frente a la Constituyente, su exigencia era nítida: que el objeto de la Constitución fuera la condición humana, de manera 
que se levantara un ordenamiento democrático "conforme a la naturaleza y a la dignidad de la persona humana" (La Pira, 1957: 50) Tres años después, la aparición en Italia de Para una arquitectura cristiana del Estado planteaba a la ciudadanía la necesidad de entendimiento de la elección política no como una mera adhesión a determinados mecanismos de técnica de gobierno, sino como una opción que "abarca la totalidad del ideario del cual la doctrina y la praxis política actúan”. Y una opción, además, básicamente vinculada a "responsabilidades morales" (La Pira, 1956: 196) El 20 de noviembre de ese mismo año 1948 de la entrada en vigor de la Constitución italiana, el presidente del Consejo de Ministros Alcide de Gasperi pronunciaba en Bruselas una conferencia sobre Las bases morales de la democracia en donde reafirmaba el compromiso del flamante ordenamiento constitucional italiano con un proyecto democrático al mismo tiempo fundamentado sobre la libertad política y la justicia social (De Gasperi, 204: 58) Y en 1951, la aparición de la primera versión, inglesa, de El hombre y el Estado, de Jacques Maritain, por tantos conceptos el maestro de Eduardo Frei Montalva, vendría a aportar una fundamentación racional a los derechos humanos, al tiempo que brindaba a los amigos y admiradores del maestro parisino una construcción alternativa al Moloch estatal cuyo abrumador impacto sobre la vida y la dignidad humana constituía uno de los centros de la inquietud política de Eduardo Frei Montalva (Maritain, 2002: 87 y ss.)

El Estado social y democrático de Derecho había procedido a la refundación del sistema democrático en Europa. Y tanto sus soluciones institucionales como sus esquemas de pensamiento le resultaban muy familiares a un Eduardo Frei Montalva que, tras ocupar entre el 14 de mayo de 1945 y el 28 de enero de 1946 el Ministerio de Obras Públicas y Vías de Comunicación de la República, convertirse el 23 de abril de 1947 en uno de los fundadores de la Organización Demócrata Cristiana de América (antes de la creación de los Nuevos Equipos Internacionales en Chaudfontaine el 2 de junio de 1947), y ser elegido el 15 de mayo de 1949 senador por Atacama y Coquimbo, se había convertido en un hombre de Estado que, en el ejercicio de sus responsabilidades políticas, habría de desplegar no únicamente un poderoso sistema de pensamiento, sino también un coherente y eficaz accionar político e institucional con el objeto de dotar de una sólida fundamentación histórico-jurídica a la construcción de una nueva propuesta democrática para el Estado de Derecho. 


\section{La justicia contra el formalismo legal "de la vida por el expediente". El proyecto democrático y republicano del senador Eduardo Frei Montalva}

Eduardo Frei Montalva consideraba que únicamente a partir de estos presupuestos, es decir, de un conocimiento de la Historia estrechamente vinculado al afán de detección de los grandes problemas de una sociedad desde sus raíces, y al compromiso con su resolución conforme a un ideal democrático que rebasa el formalismo institucional, podría dibujarse un innovador proyecto republicano, consciente de la singularidad de las exigencias que la injusticia y la desigualdad arroja sobre una sociedad, y comprometido con su resolución. Y La verdad tiene su hora, publicado en 1955, vendría a expresar el ideario de un estadista que se había transformado ya en el líder indiscutible de los cada vez más amplios segmentos políticos de la sociedad chilena comprometidos con la materialización de un vasto programa de reformas que posibilitara la creación de un moderno Estado de Derecho sustentado sobre una amplia y generosa democracia.

Uno de los jalones principales dentro de la maduración de esa renovada óptica de las instituciones del Estado de Derecho residía en la inquietud de Eduardo Frei Montalva por el hecho de que "incapaces de organizarnos y someternos a una disciplina consciente, hemos ido desgastando los fundamentos en que reposa la democracia. En vez de hacer justicia hemos preferido el formalismo legal, sustituyendo la vida por el expediente... y manteniendo, a pesar de tantas leyes, en la pobreza o inferioridad de siempre, a un gran sector del pueblo". El senador Frei estaba convencido de la capacidad transformadora de la democracia a través de un Estado de Derecho que podía y debía saber interpretar y materializar las aspiraciones de una ciudadanía que tenía derecho a "vivir con dignidad y alcanzar sin violencia una transformación de la democracia que signifique el derecho, no sólo a ser libres, sino también a participar de una manera justa de los beneficios que se alcanzan por el trabajo" (Frei Montalva 1955: 10 y 21)

En este sentido, Frei Montalva señala al "crecimiento del poder del Estado" como la más relevante característica del mundo contemporáneo. Pero ese proceso, que en el mundo colectivista no es más que una acabada herramienta de la tiranía, en el ámbito democrático puede ser un privilegiado instrumento de la libertad y del progreso económico. El líder cristianodemócrata observa cómo se reproducía, una vez más, una histórica encrucijada de magnitudes: "por una parte, la necesidad de un Estado capaz de impulsar el desarrollo... de ser el agente de las transformaciones que exige el pueblo y de realizar la justicia; y por otra, la exigencia de que su crecimiento desmesurado no ahogue la libertad personal y la iniciativa creadora". Siguiendo a uno de sus pensadores y líderes 
siempre inspiradores, y desde su juventud y su viaje a Roma al Congreso de Pax Romana en 1933, Luigi Sturzo, Frei Montalva recuerda que el sistema democrático cuenta con dos elementos definidores: "libertad como oposición al despotismo y sociedad en la cual no hay clases, castas o intereses privilegiados". Pero también que, tras la Gran Guerra, y valdría ello para después de la Segunda Guerra Mundial,

el camino hacia la libertad ha sido obstaculizado por tres factores: falta de fe en la libertad o, más exactamente, miedo a la libertad; un complejo de inferioridad frente a las tesis marxistas; y los intereses organizados de la burocracia gubernamental (Frei Montalva 1955: 29 y 39-40).

El pensamiento de Frei Montalva coincidía en el tiempo, también, con el de quien sería su amigo y uno de los más grandes chilenos de la historia: el sacerdote jesuita Alberto Hurtado, hoy canonizado, prematuramente fallecido con apenas 51 años en pleno invierno austral el 18 de agosto de 1952. Su presencia e influencia como expresión viva del compromiso social con todos los descartados por la sociedad, con los vulnerables, enfermos, y pobres, constituye una inspiración imprescindible en el Chile y en el mundo contemporáneos, y su camioneta verde un símbolo de fraternidad, de solidaridad y de voluntad cívica de concordia en la justicia. Y en sus papeles póstumos se puede encontrar una formulación muy lúcida e inteligente de una visión del sistema institucional en donde

el Estado no es, pues, en moral cristiana ni el gendarme liberal, ni la providencia omnipotente del estatismo. La misión del Estado es asegurar a las libertades particulares sus mejores condiciones de ejercicio y hacerlas converger hacia el bien común, única razón de sus intervenciones.

Pero la ciudadanía no puede permanecer inerte en este debate. De acuerdo con la óptica del sacerdote nacido en Viña del Mar,

el ciudadano no puede desentenderse de los deberes cívicos. La política está destinada a crear las instituciones de justicia social que miran al bien común. La educación, el bienestar, la libertad, el respeto de la conciencia, la organización de la vida económica, la defensa de la patria, dependen de las leyes. A nadie, pues, le es lícito desentenderse... (Hurtado 2006: 104 y 116)

Y porque nadie puede abjurar de su responsabilidad cívica, la democracia se enfrenta así, según Frei Montalva, a su "drama” constitutivo: "los que viven en ella, por regla general, se niegan a los sacrificios voluntarios y progresan, en cambio, los que ofrecen ventajas, aunque estén ciertos de que no podrán cumplirlas". Pero este proceso afronta, de acuerdo con el mismo razonamiento, el hecho de que 
en su esencia, la democracia es un sistema que confía en el consentimiento y, por consiguiente, apela a la razón de cada uno de los que componen la sociedad. La tentación de cada hombre es siempre renunciar a la razón y entregarse al instinto.

Y esa tentación es igualmente poderosa en el administrador y en el administrado, porque

en el gobernante la tentación es muy fuerte, en especial con el poder del Estado. La ley le resulta siempre una traba. Y en el ciudadano es difícil mantener la fe en el proceso legal, al parecer más lento, porque siempre la imagen del instinto desencadenado tiene más atracción que la imagen de la prudencia y de la justicia (Frei Montalva 1955: 48, 49-50).

Por eso el principio de subsidiariedad cobra tanta fuerza en el pensamiento de Eduardo Frei. Y para reforzar su argumentación acude a la experiencia de las formas de creación, recordando que "los estados monolíticos y totalitarios no han dejado normalmente recuerdos en el arte, en la literatura, en la música, en las ciencias mismas". Para el jurista nacido en Santiago de Chile, "así como no es conveniente el intervencionismo pequeño, en el orden económico, tampoco lo es en el administrativo". Y, en ese sentido, la historia ofrece un testimonio sumamente inspirador porque

aun brilla, en cambio, la luz que encendieran las ciudades-estado en la antigüedad, y Europa entera fue creada en las ciudades que defendieron sus fueros y libertades y que con sus ayuntamientos y corporaciones tenían una espléndida vida, no ahogada por un omnímodo poder central. Sus calles están pobladas de monumentos construidos anónimamente por el pueblo, que quería lo suyo, que admiraba a sus artistas, pensadores y sabios. Los nombres de Atenas y Florencia, para no citar tantos otros, hablan por ellos (Frei Montalva 1955: 114).

El horizonte del Estado de Derecho queda así vinculado a la libertad cívica para crear, emprender, innovar y construir, y no a la intervención de las formas estatales. Decía Robert Schuman que "la democracia es una constante creación". Pero, añadía Schuman, también discípulo y amigo de Jacques Maritain, que "la democracia, sobre todo, no se improvisa" (Schuman, 2006: 47). Eduardo Frei Montalva habría de demostrar hasta qué punto la praxis política democrática no puede ser nunca fruto de la improvisación. 


\section{La razón organizada y el movimiento firme de los pueblos}

En Pensamiento y acción, publicada en 1956, casi diez años antes de la histórica elección presidencial de 1964, y la siguiente entre las grandes obras de madurez del ya conocido político y líder de la todavía minoritaria pero muy respetada "Falange Nacional", en la víspera de su transformación en el Partido Demócrata Cristiano, se propone desde su mismo enunciado toda una síntesis de la óptica vital y estratégica de Eduardo Frei Montalva, cuya óptica adquiría ya unos perfiles de análisis y de propuesta de interpretación de plena madurez política y vital, y tanto en su pensamiento jurídico como en su concepción del Estado.

Ese mismo año 1956 Frei intervenía en el Congreso Internacional Demócratacristiano. Y su interpretación de la Historia y del porvenir de la democracia es ya nítida. Existen unas "fuerzas históricas" que señalan que "ésta es la hora de la democracia cristiana". Esas fuerzas están "dentro de su sentido y de su corriente", para alumbrar la esperanza democrática. Y, en nombre de esa esperanza, Frei Montalva puede preguntar:

¿no podemos construir una sociedad pacífica, fraternal, humana? Cuando ya otros continentes nos han entregado la contribución de religiones milenarias, de culturas inmensamente ricas, de arte, de belleza, de creación, ¿no podemos dar una respuesta, y decir: en esta hora, nosotros, los pueblos de América, damos el ejemplo y hemos construido una democracia pacífica? ¿No podemos decir: aquí, en esta tierra, sin sangre y sin violencia, los hombres se han unido en una hermandad? ¿...En esta tierra, por la razón organizada y por el movimiento firme de los pueblos, el Estado, la sociedad, ha ido suprimiendo la injusticia y las diferencias; aquí, en esta tierra de América, a la sombra de sus árboles, en las laderas de sus montañas, en las riberas de sus valles, ha nacido la democracia, y los cristianos han cooperado libremente, generosamente a que se construya esta casa del hombre? (Frei Montalva, 1993: 245).

La transformación de la Falange Nacional y la consiguiente creación del Partido Demócrata Cristiano en 1957 coincide, igualmente, con la maduración de un pensamiento mucho más sensible a la acuciante problemática social del país. Al año siguiente, uno de los numerosos brillantes jóvenes pensadores próximos a Eduardo Frei, Jorge Ahumada, elabora En vez de la miseria, un libro esencial a la comprensión del proyecto de reforma del sistema democrático y de consolidación y ampliación de las bases conceptuales y sociales sobre las que se sustentaba el Estado de Derecho chileno, y muy especialmente del proyecto considerado desde la perspectiva socialcristiana, Ahumada reconoce que "existe una conciencia nacional y hay manifestaciones evidentes de ansiedad por encontrar soluciones", pero añade igualmente que, para algunos 
"todos los problemas chilenos se resuelven poniendo términos a la intervención del Estado" y "para otro grupo, tan numeroso y desorientado como el anterior, la interpretación de los problemas chilenos la escribieron Marx y Lenin". Adicionalmente,

los problemas principales de los gobernantes se encuentran... en la fijación de las grandes líneas directrices, en la sabia elección de los especialistas y en su eficiente coordinación. Para estos propósitos la intuición y la cultura son herramientas indispensables, pero no bastan para hacer un gobierno eficiente (Ahumada C., J., 1958: 15-16 y 19).

Jorge Ahumada aboga por encontrar en la asesoría técnica uno de los caminos hacia la eficiencia de la política nacional. Pero, siempre, sabiendo que se trata de una condición necesaria, pero no suficiente, para la modernización de las instituciones públicas y la potenciación del proceso de toma de decisiones en el marco de un Estado de Derecho en donde

la ineficacia de los ministros de Estado como consejeros e informantes del Presidente se agrava por dos razones adicionales; por su tradicional inestabilidad, que les hace difícil su familiarización con los problemas con que deben lidiar, y por su función política, que les obliga a poner un ingrediente partidista a todas las soluciones que proponen. El Presidente, en virtud de haber culminado su carrera política, está actuando más para la historia y, en consecuencia, con más objetividad y con menos compromisos (Ahumada C. 1958: 38-39).

Eduardo Frei Montalva recoge los planteamientos de su entusiasta amigo y camarada cuando, en el discurso de cierre de su primera campaña presidencial, el 2 de septiembre de 1958, señala que

el país no podría sostener un régimen estable de democracia y de paz gobernado por quienes cualesquiera que sean sus condiciones personales, no representan el sentido del tiempo, las necesarias transformaciones, y que no son la expresión ni de la clase media ni de los trabajadores chilenos, y que en definitiva se aferran soberbios a sus privilegios.

Estos planteamientos alcanzarán en su segunda campaña presidencial, esta vez plenamente exitosa, su mejor expresión el 21 de junio de 1964 en su célebre "Discurso de la Patria Joven", cuando anuncia a la multitud reunida en el Parque Cousiño que

vamos a hacer un Gobierno que no sólo va a garantizar el progreso económico, la justicia y la incorporación del pueblo en forma responsable a la tarea y al beneficio, sino que vamos a hacer esta tarea en libertad y en respeto a los derechos de la persona humana. En libertad religiosa, sindical, política y de 
expresión. Porque nosotros, durante toda nuestra vida, hemos sido garantía de respeto al derecho y a la libertad (Frei Montalva 1993: 261 y 295).

La "Revolución en Libertad" se presenta, y se presenta especialmente ante la juventud en una nación joven, como una propuesta de transformación política y social, cuando no de reconstrucción democrática de la arquitectura del Estado de Derecho, pero realizada con plena sumisión a la ley. La misma "Démocratie Nouvelle" propugnada por el MRP francés a partir de su III Congreso, y basada en la liberación del ser humano "de todas las opresiones, de todas las servidumbres que impiden su pleno desarrollo y su libre crecimiento material, espiritual y moral". Pero, con el mismo énfasis, el decidido propósito de liberar también

al Estado de la servidumbre a la que le ha conducido y donde la mantiene un régimen económico y social que, al aceptar el beneficio como principio regulador de la vida económica, y al reservar a unos pocos el privilegio de beneficiarse de las riquezas materiales y de los frutos del trabajo común, la reserva al mismo tiempo el poder, las responsabilidades y la cultura (Mouvement Républicain Populaire, 1947: 57).

El MRP había adoptado una orientación profundamente reformista a partir del Informe que bajo la denominación "Démocratie et Libération" había presentado su joven secretario general adjunto, el bretón Albert Gortais, y que ponía en validez los principios liderados desde la Resistencia en Lyon por Gilbert Dru, ahora expresados muy nítidamente: la democracia política no sería más que una mera ficción si, al mismo tiempo, no venía acompañada de una verdadera democracia económica y social. Y ello significaba que "la democracia no vivirá, ni progresará, si no se trasforma y se convierte en total" (Gortais, 1947: 37) Y entre 1964 y 1970, Eduardo Frei Montalva lideraría, desde la Presidencia de la República chilena, uno de los empeños más comprometidos con el esfuerzo por crear una democracia viva, en progreso, y total, en el itinerario histórico del Estado de Derecho.

\section{Revolución en Libertad: un espíritu lúcido y un corazón heroicamente generoso}

La victoria de Eduardo Frei Montalva en las elecciones presidenciales del 4 de septiembre de 1964 con más de un $56 \%$ de los sufragios y más de 17 puntos de diferencia respecto a su adversario, el socialista Salvador Allende Gossens, representa la materialización de ese ideario de verdadera democracia económica y social. Y el presidente electo no alberga la menor duda acerca de 
la significación de su victoria. El 5 de septiembre de 1964, apenas unas horas después de imponerse en las elecciones presidenciales, redacta su primera carta como primer mandatario electo, y se la dirige al Papa Pablo VI. En un magnífico francés, le manifiesta su compromiso con las clases populares que le han otorgado su confianza en la misma medida que se muestra sabedor de la dureza de las tareas gubernamentales que le aguardan, para concluir por expresar que se encuentra "clairement conscient des distinctions qui doivent être maintenues entre doctrine et politique, je ne m'en sens pas moins responsable, comme catholique convaincu, de la promotion qu'exigent en Amérique Latine cet approfondissement et cette élaboration doctrinale" (ACMEFM 0.49 C.C./2.2IT).

Doctrina y política. Pensamiento y acción. Si el fundador del Sillon y uno de los fundadores del MRP, Marc Sangnier, definía a la democracia como "el poder del pueblo para la libertad", la asunción responsable del poder no representa más que una condición necesaria, pero en absoluto suficiente, en el ejercicio del mandato democrático. Cuando, de regreso de su histórica gira europea de 1965, Eduardo Frei Montalva escribió el 3 de noviembre del mismo año a Konrad Adenauer tras la entrevista que ambos mantuvieron en Rhöndorf junto a doña Maruja Ruiz-Tagle como histórico testigo, era perfectamente consciente de "haber cumplido la primera etapa al ganar el poder", pero también de que "tenemos por delante un camino duro y difícil, que sólo podemos recorrer con éxito cumpliendo con el programa que nos hemos trazado" (Frei Montalva, 1965, ACMEFM, C.C/2.1-AL).

En el primer año del mandato presidencial de Frei, en 1965, se publica $E l$ desarrollo de la Nueva Sociedad en América Latina, un libro cuyos jóvenes autores son Julio Silva Solar y Jacques Chonchol, también encuadrados en el Partido Demócrata Cristiano, pero quienes prontamente protagonizarán una de sus más características escisiones en dirección al campo de la Unidad Popular, creando el Movimiento de Acción Popular Unitaria (MAPU) dentro de una estrategia de abierta convergencia con el marxismo, entendiendo que la misión del cristianismo y del cristiano es combatir el capitalismo y, por lo tanto, su política de alianzas en todo momento debe tender a la conciliación con las fuerzas populares cuyo supremo objetivo es el mismo. La obra aparece en el mismo año de la desaparición prematura, en plena madurez a sus apenas 50 años, de Jorge Ahumada, y viene a suceder en el tiempo al análisis y las propuestas del gran economista y en buena medida redactor del programa económico y social del candidato Frei Montalva en 1964. Y viene a testimoniar que, para un segmento importante de la juventud chilena, incluida la democristiana, la estrategia reformista empezaba a ser descartada casi sin haber sido puesta en marcha. 
En este sentido, ambos jóvenes pensadores sostienen que el cristianismo "expresa la fe y esperanza del hombre en su humanidad plena y su lucha continua por encaminarse a ella hasta alcanzarla". Y "son los desheredados, los pobres, quienes hacen suya esta esperanza y se reúnen en ella. Todo se renovará... Comunión universal, comunicación (el acto en su recuerdo que Jesús dejó a sus discípulos fue la comida común; todos participan del mismo pan y del mismo vino y se unen ahí fraternalmente) El fin último es la suprema comunión con Dios". Por eso, el horizonte político e institucional de la acción democrática de inspiración cristiana resulta inequívoco para ambos:

todo es de todos, sin propiedad sin clases, sin dinero, sin nada que separe al hombre del hombre (que todos sean uno; se reconocerán por el amor, se encontrará el que se pierda para su egoísmo; dad y recibid gratuitamente) Reino de libertad (sin opresores), Reino de paz (sin guerras ni antagonismos destructivos), Reino universal (alcanza a todos los pueblos, razas y lugares), Reino de abundancia (manarán los bienes, dicen los profetas) (Silva Solar y Chonchol 1965: 18-19).

Ese mismo año, con motivo de su impactante gira europea, que determinará el establecimiento de una relación de profunda amistad con figuras como Konrad Adenauer, Charles de Gaulle, Isabel II de la Gran Bretaña o Balduino de Bélgica, y en el discurso que pronuncia en El Elíseo el 16 de julio de 1965 en su transcurso, el presidente Frei Montalva traza de manera magistral la pertenencia de la República de Chile a un mismo tronco político, jurídico e institucional compartido con la República Francesa:

hay algo que une a mi tierra y a mi pueblo tan joven, con esta antigua nación:
es el amor a la libertad, aunque llegue a lo excesivo; es la renovación constante
de las instituciones jurídicas que la ordenan; es el sentido del equilibrio en el
juicio y en la acción; es, sobre todo, una altiva afirmación de su independencia;
es la admiración por la inteligencia y el respeto profundo por la dignidad de la
persona humana (Frei Montalva 1993: 306).

En este sentido, para algunos de los jefes de Estado europeos, por no decir los protagonistas del gran tercio de siglo del cambio democrático y del Estado de Derecho en Europa, el proyecto político del presidente chileno habría de merecer una valoración que desbordaba el marco estrictamente institucional. $\mathrm{O}$, posiblemente, era la más política de todas las valoraciones. Balduino de Bélgica, por ejemplo, en carta enviada desde el Castillo de Laeken a comienzos de 1966, habría de referirse a "l'importance de votre tâche aux yeux des autres peuples d'Amérique Latine pour lesquels le succès de votre entreprise constitue un suprême espoir" (Balduino de Bélgica, 1966, ACMEFM: 051). 
Coincidía el rey de los belgas con el propio gran inspirador doctrinal del pensamiento de Eduardo Frei, Jacques Maritain, quien en carta enviada desde Toulouse el 6 de mayo de 1967, tras recibir una invitación para visitar Chile que no pudo atender, valoraba la "Revolución en Libertad" con la misma conciencia histórica y democrática, afirmando que

no existe tarea más difícil en este mundo. Y Ud. solo (gracias le sean dadas) la ha emprendido en este pobre universo. Es un gran testimonio ante Dios, ese gran testimonio rendido a la política cristiana y al espíritu evangélico en el campo temporal por un espíritu lúcido y un corazón heroicamente generoso. Sea lo que suceda aquí abajo este honor incomparable quedará para siempre unido a su nombre. Y es por eso que sigo con un interés tan apasionado todo lo que concierne a la obra que Ud. lleva a cabo en Chile, y cuya dimensión es inmensa no sólo para América Latina, sino para todas las naciones (Maritain en Frei Montalva 1989: 177).

Pero probablemente es en la carta que le dirige a Eduardo Frei su también amigo, el vicepresidente de los Estados Unidos Hubert Humphrey, el 15 de septiembre de 1968, en donde con más lucidez se expone la histórica problemática del proyecto democrático de ampliación de los derechos sociales y las bases sustentantes del Estado de Derecho a través de iniciativas de reforma política en el tiempo y en muchos de sus objetivos paralelas como la "Gran Sociedad" y la "Revolución en Libertad". Hubert Humphrey abiertamente afirma:

\begin{abstract}
You are atempting the most difficult of all political tasks - to achieve a fundamental structure reform of the economy and of society within a short period of time, and to accomplish this within a democratic constitutional system. In a highly politicized country like Chile, this must be accomplished in the face of opposition from a tightly-disciplined Marxist Left and an embittered, oportunistic Right.

In your country and in ours, the younger generation feels that reformist political leaders move too slowly. That is the perennial dilema of progressive democratic government -to move as rapidly as one can, but as gradually as one must-. The outcome of the experiment you have undertakan -yes, the revolution in libertyis not only decisive for Chile, but crucial to the fortune of the entire Continent. Although obstacles will continue to be formidable, I am confident that you will succeed" (Humphrey, 1965, ACMEFM, 053, 053-057).
\end{abstract}

Cuando en sus Memorias Lyndon B. Johnson hubo de explicar en qué consistía la "Gran Sociedad", tras explicar que no había sido "un ideal visionario y utópico en mi imaginación", había sostenido que, en primer lugar, se trataba de una "extensión de la Declaración de Derechos", entendiendo que "en nuestra época, un concepto más amplio de la libertad dice que todos 
y cada uno de los americanos tiene derecho a un cuerpo sano, a una plena educación, a un hogar decente y a una oportunidad para desarrollar lo mejor de sus talentos" (Johnson, 1971: 119-120) Un concepto más amplio de la libertad, inseparable de una vida digna, educada, sana y con oportunidades para todos, era el proyecto que, en consonancia con los grandes líderes reformistas de su tiempo, intentaba aplicar en Chile Eduardo Frei Montalva. Un nuevo Estado de Derecho y una nueva democracia para una también nueva sociedad.

La extraordinaria dificultad de la tarea emprendida por la administración Frei Montalva era perfectamente analizada por una figura que a lo largo de 1968 habría de emprender una campaña presidencial finalmente coronada con la derrota frente a Richard Nixon, precisamente, enarbolando los mismos principios reformistas del Estado de Derecho de aplicación "no tan rápidamente como uno puede, sino tan gradualmente como uno debe", que habrían de ser descartados por una sociedad en plena polarización. En ese contexto, Eduardo Frei Montalva urgía en carta del 30 de agosto de 1968 a Marino Rumor, como presidente de la Internacional Demócrata Cristiana, a la celebración de una reunión que posibilitara el "intentar una posición conjunta para enfrentar algunos de los problemas más salientes en esos campos, especialmente frente a las nuevas circunstancias de la política internacional" (Frei Montalva 1968, ACMEFM: C.C./2.2-IT).

Sería en el final de su mandato presidencial, y especialmente en su postrero Mensaje Presidencial al Congreso Pleno, el 21 de mayo de 1970, y tras defender al poder legislativo y al Estado de Derecho, pero condenando al mismo tiempo cualquier tentación estatista y propugnando la descentralización política, cuando Eduardo Frei Montalva procediera precisamente al análisis de la "Revolución en Libertad", partiendo de

la superioridad de la democracia como método para el cambio social" para afirmar que se ha realizado "una reforma agraria dentro del espíritu de la ley, la igualdad de oportunidades para todos los chilenos para llegar a los más altos niveles del saber y la cultura la dignidad de cada hombre y mujer chilena para organizarse libremente y luchar en defensa de sus legítimos derechos, la batalla por el perfeccionamiento de nuestra soberanía nacional y su real independencia al recuperar el dominio de sus riquezas básicas, la modernización de nuestras actividades en todos los ámbitos de la vida nacional... (Frei Montalva 1993: 399).

Un legado gigantesco, pero no refrendado en las elecciones presidenciales del 4 de septiembre, cuando el electorado se fracturó en tercios que hicieron imposible la proclamación inmediata del candidato más votado, Salvador Allende, líder de la UP, al no alcanzar el 50\%, correspondiendo al PDC la responsabilidad de proceder a su respaldo en sesión del Congreso Pleno, lo que se produjo el 24 de octubre siguiente tras la concertación de un Estatuto 
de Garantías Democráticas por el Partido Demócrata Cristiano y la Unidad Popular. Se cerraba, así, la experiencia histórica de la "Revolución en Libertad". Y comenzaba el no menos histórico mandato presidencial de Salvador Allende.

\section{Conclusiones: un Estado de Derecho que no viene de la fuerza ni del poder, y que sabe hacer frente a las crisis de civilización}

Eduardo Frei Montalva había explicado ya en los primeros días de junio de 1973, en el duodécimo Congreso de la Democracia Cristiana italiana, cómo el sistema democrático debía ser capaz de desplegar una lectura creativa de las corrientes profundas de la Historia y de la nueva naturaleza de los procesos políticos para que el Estado de Derecho fuera también capaz de afrontar una crisis mundial que en absoluto era económica o material, sino una auténtica "crisis de civilización":

La prodigiosa expansión económica ha estado acompañada por un sistema progresivamente alienante por su propia naturaleza. La crisis no es sólo económica. Es una crisis de civilización en el sentido del hombre, de los medios y los fines.

...Ha llegado el momento, como lo dijera el actual Pontífice, de dar un contenido histórico, económico y político a la doctrina social de la Iglesia. Esta no puede venir de la fuerza ni del Poder. Sólo será creadora si nace de la conciencia de los hombres y se proyecta en un nuevo modelo de sociedad humana, que no tiene sentido si no fluye de la libertad de cada hombre, y se refleja en una comunidad en que cada uno tenga una participación creadora profundamente vital y humana.

Nunca habrá una progresión en un sentido verdaderamente humano y sólido sino a través del ejercicio de su propia responsabilidad que lo educa para ser libre.

Sólo así se puede construir una sociedad personalista, comunitaria, pluralista y democrática.

Requiere esto un esfuerzo intelectual de la mayor magnitud, en que toda audacia es permitida, donde la imaginación creadora de los grupos políticos, culturales, de las élites, de obreros, de campesinos y sobre todo de la juventud, tienen un camino abierto.

Esta empresa intelectual y política supone un enorme esfuerzo moral, una idea de servicio y de acción, pero sobre todo una tarea de reflexión y de profundidad intelectual sin precedentes... (ACMEFM 262 EFIN/ 1-04).

Tras el golpe de Estado de 11 de septiembre de 1973, y el establecimiento de una dictadura militar encabezada por Augusto Pinochet, quien desde el principio habría de contemplar con hostilidad tanto el mandato de legitimidad democrática como el fino sentido jurídico -y el manejo del sentido del humor- 
de Eduardo Frei Montalva, virtudes que habría de exhibir durante la campaña del referéndum constitucional de 1980 (Vial, 2003: 433) la visión del presidente Frei acerca de la democracia se hace rotunda:

la historia de Chile se confunde con la historia de la democracia chilena, respetada y elogiada universalmente, y era éste nuestro privilegio y honor, y así pudimos sentirlo cuando tuvimos la oportunidad de representar a Chile en Europa y América.

Y, partiendo de estos presupuestos, el análisis de Frei se dirige contra los enemigos del Estado de Derecho. En primer término, contra quienes

renegaron de nuestra democracia, que vieron sólo sus defectos, o que, con apresuramiento y ligereza, a veces criminal, quisieron arrojarla por la borda para realizar sus acalorados ensueños sin respeto algunos por la realidad, pueden hoy apreciar y saber lo que perdieron y llorar sobre sus ruinas.

\section{Pero recuerda igualmente que}

es fácil decir que la democracia es ineficaz y vacilante; pero, cosa curiosa, los mismos que alaban sin medida los progresos de EEUU y de Europa Occidental y abominan de las dictaduras comunistas, podrían preguntarse cómo esos pueblos han llegado a tan altas posiciones si la democracia es tan ineficiente y las dictaduras son tan eficaces (Frei Montalva 2011: 64).

Por eso, cuando en 1977 se conmemoró el décimo aniversario del fallecimiento de Konrad Adenauer, y fue invitado a examinar la determinante dimensión histórica del alemán más grande junto con el joven Helmut Kohl, entonces líder de una CDU en la oposición, y Golo Mann, el hijo catedrático de Historia Moderna de Thomas Mann, Eduardo Frei Montalva, como el único autor participante en el homenaje entre los grandes mandatarios a los que distinguió Konrad Adenauer todavía vivo, pudo recordar a su amigo afirmando, en primer lugar, que como

demócrata integral, levantó los cimientos de un sistema político que, junto con garantizar una autoridad eficaz, permitió el ejercicio pleno de las libertades individuales y sociales, lo que significó un dique contención contra las fuerzas que buscan siempre la destrucción.

Pero, igualmente, valorar también la obra emprendida cuando tras la Segunda Guerra Mundial

y de la lucha contra el nazi-fascismo, Europa buscó un camino y lo encontró

a través de una respuesta de inspiración cristiana y de irrenunciable vocación 
democrática expresada por Schuman, De Gasperi y el propio Adenauer, lo que hizo posible surgiera una comunidad integrada, como ejemplo de lo que pueden la inteligencia y la voluntad, cuando se liberan de los egoísmos y los rencores del pasado (Frei Montalva, 1977: 4-5).

Eduardo Frei Montalva había defendido siempre que, en efecto, la inteligencia y la voluntad prevalecían sobre los prejuicios, la polarización, la fragmentación y la fractura del cuerpo social y político cuando el Estado de Derecho se instalaba en la racionalidad, y operaba a través del instrumento liberador por excelencia: la ley. Pero el Estado de Derecho, en la perspectiva política y jurídica de quien se había convertido en su servidor por excelencia, era también, se diría que, sobre todo, una cuestión de estilo. Y el año 1981, en plenas postrimerías de una existencia truncada por culpa del miserable magnicidio perpetrado por la dictadura, esa racionalidad exigía asumir una forma eminente del coraje democrático llamada moderación:

\begin{abstract}
Desgraciadamente los pueblos -¿cuáles no?- atraviesan por encrucijadas en que pareciera inútil la razón. La gente se va proyectando de tal manera que toda tentativa de comunicación, de análisis, de conversación, aparece como una debilidad. Los hombres fuertes son los que predominan con criterios simples y tajantes: a un lado están los buenos y al otro los definitivamente malos. Los que no están de acuerdo con la tendencia dominante o son ingenuos o los mueven las pasiones más viles y despreciables.

En estos tiempos no hay un coraje mayor, diría yo, supremo: no dejarse arrastrar por los propios partidarios y ser moderado, una palabra que, en esas circunstancias, adquiere para los energúmenos dominantes, una connotación bastante sucia (Frei Montalva, 1989: 59-60).
\end{abstract}

La moderación, y sobre todo la audacia de la moderación, habrían de constituirse no únicamente en una cualidad del servidor público, y no digamos del hombre de Estado, sino en una exigencia del funcionamiento de las instituciones y del propio desenvolvimiento del Estado de Derecho. Y, en su último libro, El mensaje humanista, aparecido en 1981, apenas semanas antes de su asesinato, tras la farsa de referéndum organizada en el invierno austral de 1980 por el dictador para su permanencia en el poder conquistado de manera sangrienta, y detentado durante 16 años, Eduardo Frei Montalva vino a defender, precisamente, la libertad, sosteniendo en plena continuidad con su mensaje histórico que

no es, pues la libertad económica la que engendra la libertad humana y el verdadero desarrollo de la comunidad toda, sino que es la consecuencia de una visión del hombre, de su libertad intrínseca, la que genera el adecuado funcionamiento de todo el cuerpo social y de la economía, en correspondencia con los valores que ocupan un lugar esencial y prioritario. 
Por eso, tal y como corona su despliegue argumental Frei Montalva, "la libertad no es un don superpuesto ni un atributo insubstancial". Ser libre es esencial a cada ser humano. Y los poderes públicos no pueden hacer más que reconocer y desplegar una efectiva tutela judicial sobre la libertad. El Estado de Derecho es un Estado de libertad y de creencia en la libertad, "de fe en la libertad", como diría Karl Jaspers. La libertad no es condición suficiente del Estado de Derecho, pero sí condición necesaria (Frei Montalva, 1993, 631-632).

Acaso su propio epitafio ante la historia y ante la lealtad a los principios inspiradores del Estado de Derecho lo había escrito el propio Eduardo Frei Montalva cuando el 29 de abril de 1969 le escribió a su amigo Charles de Gaulle una sentida carta con motivo de su dimisión de la presidencia de la República Francesa. El propio estadista francés, por cierto, habría de responderle el 8 de mayo siguiente manifestándole que "J'ai été, je vous l'assure, très touché de votre essage et de l'accent si amical que vous lui avez donné" (De Gaulle, 1969, ACMEFM: 054).

Lo significativo de la carta del presidente chileno residía en que su mensaje a Charles de Gaulle, su amigo, y un amigo que no únicamente quiso de manera entrañable al presidente chileno, sino que le consideró como una de las grandes figuras políticas del siglo, puede hoy aplicársele enteramente con el sólo cambio de Francia por Chile: "ha cumplido una tarea histórica que está más allá de triunfos o derrotas. Su nombre estará imperecederamente ligado a la historia de Francia y, en muchos aspectos, a la historia universal de nuestro tiempo" (Eduardo Frei, 1969, ACMEFM: C.C./2.1-FR). Lucano demostró en La Farsalia que no existen batallas y, por lo tanto, victorias o derrotas. Eduardo Frei Montalva cumplió su histórica tarea. Y, durante su etapa más brillante, hizo confluir la historia de la República de Chile con la historia universal del Estado de Derecho.

\section{Bibliografía:}

Ahumada C., J., En vez de la miseria. Santiago de Chile. 1958.

Aylwin Azócar, P., El reencuentro de los demócratas. De la dictadura a la democracia. Santiago de Chile. 2018.

Balduino de Bélgica, Lettre Eduardo Frei Montalva, Château de Laeken, 31 janvier 1966. Archivo Casa Museo Eduardo Frei Montalva (ACMEFM): 051.

Berlinguer, E., Gobierno de unidad democrática y compromiso histórico. Discursos 1969-1976. Madrid. 1977. 
Bichet, R., La Démocratie Chrétienne en France. Le Mouvement Républicain Populaire. París. 1980.

De Gasperi, A., L’Europa. Scritti e discorsi. A cura di María Romana De Gasperi. Brescia. 2004.

De Gaulle, C., Lettre Eduardo Frei, Colombey, 8 mai 1969. ACMEFM: 054.

Frei Montalva, E., La verdad tiene su hora. Santiago de Chile. 1955.

-Pensamiento y Acción. Santiago de Chile. 1956.

- Carta al Papa Pablo VI. Santiago de Chile, 5 de septiembre de 1964. ACMEFM: 049. C.C./ 2.2-IT.

-Carta a Konrad Adenauer. Santiago de Chile, 3 de noviembre de 1965. ACMEFM: C.C./ 2.1-AL.

-Carta a Mariano Rumor. Santiago de Chile, 30 de agosto de 1968. ACMEFM: C.C./ 2.2-IT.

-Carta a Charles de Gaulle. Santiago de Chile, 29 de abril de 1969. ACMEFM: C.C./2.1-FR.

-Conferencia en el XII Congreso de la Democracia Cristiana. Roma, 6-10 de junio de 1973. ACMEFM: 262, EFIN 1-04.

-"Presencia de Adenauer". Frei Montalva, E.; Kohl, H.; Mann, G., Konrad Adenauer. Presencia, patrimonio y postulado, pp. 3-6. Buenos AiresSantiago de Chile. 1977.

-Memorias. 1911-1934 y Correspondencias con Gabriela Mistral y Jacques Maritain. Santiago de Chile. 1989.

-Obras escogidas. 1931-1982. Santiago de Chile. 1993.

-Chile desconocido. Santiago de Chile. 2010.

-El Mandato de la Historia y las Exigencias del Porvenir. Santiago de Chile. 2011.

Gazmuri, C., Eduardo Frei Montalva y su época. 2 tomos. Colaboraron P. Arancibia y Á. Góngora. Santiago de Chile. 2000.

Giovagnoli, A., Il caso Moro. Una tragedia repubblicana. Bologna. 2005.

Gortais, A., Démocratie et Libération. París. 1947.

Humphrey, H., Letter to Eduardo Frei Montalva, Washington, january 15, 1968. ACMEFM: 053, 053-057.

Hurtado, A., Moral Social. Obra póstuma de San Alberto Hurtado S. J. Santiago de Chile. 2006.

Johnson, L. B., Memorias de un presidente. 1963-1969. Barcelona. 1971.

La Pira, G., Para una arquitectura cristiana del Estado. Buenos Aires. 1956.

-Examen de conciencia frente a la Constituyente. Buenos Aires. 1957.

Letamendia, P., Le Mouvement Républicain Populaire. Histoire d'un grand parti français. París. 1995.

Maritain, J., El Hombre y el Estado. Madrid. 2002.

Moro, A., Una política per i tempi nuovi. Roma. 1969. 
Mouvement Républicain Populaire, Vers une Démocratie Nouvelle. París. 1947. Schuman, R.: Para Europa. Madrid. 2006.

Silva Solar, J.; Chonchol, J., El desarrollo de la Nueva Sociedad en América Latina. Santiago de Chile. 1965.

Vial, G., Pinochet. La biografia. 2 tomos. Santiago de Chile. 2003. 
